\title{
Solid Pseudopapillary Neoplasm (SPN) of the Pancreas: A 7-year Study in A Tertiary Level Teaching Hospital in Bangladesh
}

\begin{abstract}
Solid pseudopapillary neoplasm (SPN) of the pancreas, also referred to as Frantz's tumour, is a rare tumour and represents $1-3 \%$ of all pancreatic tumours, which typically affects young women without significant clinical symptoms. This cross-sectional study was done in the Department of Pathology, Bangabandhu Sheikh Mujib Medical Un iversity (BSMMU) between January 2009 and December 2015. A total of nineteen cases of solid pseudopapillary neoplasm (SPN) of pancreas were detected in patients and included in this study. In all the patients the diagnosis was confirmed by histopathology after the surgery. Tumours were nodular, cystic or solid-cystic, often encapsulated. Some of them were received as irregular fragmented pieces, as intact removal was not possible. Cut surfaces were partly grey-white and partly tan-brown with cystic degeneration. Areas of necrosis and hemorrhage were present in all the specimens. The age range was of $14-45$ years (mean age $26.9 \pm 3.7$ years) (Table-I). Among the tumours, 18 were found in female patients, while only 1 was from male patient. In all the cases, preoperative imaging contributed to diagnosis of an abdominal mass in the patients. 11 of these were reported as pancreatic mass, while 3 as pancreatic cystic mass, 2 as retroperitoneal mass, 2 as mesenteric mass and only 1 as adrenal mass. Tumoursize ranged from 6 to $19 \mathrm{~cm}$ (mean size $9.3 \pm 1.5 \mathrm{~cm}$ ). 7 tumours were solid and cystic in nature, while 8 were solid and 4 were only cystic. Complete capsule was found in 17 specimens. Calcifications were found in only 5 specimens. Surgical resection was found generally curative. In our study, absence of metastasis suggests that these tumours hardly show aggressive clinical behaviour. However, follow-up is important to observe potential local recurrence and metastasis.
\end{abstract}

Chowdhury $\mathrm{MA}^{1}$, Asaduzzaman ${ }^{2}$

CBMJ 2020 July: vol. 09 no. 02 P: 34-38

Key words: Pancreatic tumour, solid pseudopapillary neoplasm.

\section{Introduction}

Neoplasms of the pancreas are the fourth most common cause of cancer-related death around the world. ${ }^{1}$ These tumors are often difficult to detect due to their location; most patients present with non-specific symptoms or clinicians discover them on incidental radiographs for different conditions. ${ }^{2,3}$ Solid pseudopapillary neoplasm (SPN) of the pancreas, also referred to as Frantz's tumour, is a rare tumour and represents $1-3 \%$ of all pancreatic tumours, which typically affects young women without significant clinical symptoms. $^{4,5}$ SPN usually shows an indolent behavior and only rare cases recur and/or metastasize after complete resection. ${ }^{6}$ It is composed of monomorphic cells forming solid and pseudopapillary structures, frequently showing hemorrhagiccystic changes, and variably expressing epithelial, mesenchymal and endocrine markers. The first case report was documented in 1959 and since then multiple case reports have been documented on the various surgical approaches for SPT. Until its inclusion in the World Health organization (WHO) classification of pancreatic tumors in 1996 as "solid pseudopapillary tumour" of the pancreas, the tumor has been described by different names in the literature such as

1. Dr. Mehdi Ashik Chowdhury, Assistant Professor, Department of Pathology, Jahurul Islam Medical College, Bajitpur, Bangladesh.

2. Dr. Asaduzzaman, Lecturer, Department of Pathology, Sheikh Sayera Khatun Medical College, Gopalganj-8100; Bangladesh.

Address of correspondence:

Email:dr.human.ma@gmail.com 
"papillary epithelial neoplasm of pancreas", "solid and cystic tumor of the pancreas", "adenocarcinoma of pancreas of childhood", "papillary-cystic tumor" and "solid and papillary epithelial neoplasm". The term SPN gained wide acceptance and is currently the most frequently used name for this entity. ${ }^{8}$ However, only few reported cases are evident in our country to date. Hence, the present study aims to present the findings of nineteen cases of SPN, as we encountered over seven years in the Department of Pathology, Bangabandhu Sheikh Mujib Medical University (BSMMU).

\section{Methods}

This cross-sectional study was done in the Department of Pathology, Bangabandhu Sheikh Mujib Medical University (BSMMU) between January 2009 and December 2015. A total of nineteen cases of solid pseudopapillary neoplasm (SPN) of pancreas were detected in patients and included in this study; they were further investigated and treated within this time frame. Data represented as clinicopathological characteristics, such as age, gender, location, preoperative findings, tumour size. The investigations performed included routine blood investigations, chest x-ray, CA-19-9 level and either an ultrasound or a CT Scan of the abdomen.

\section{Gross appearance:}

In all the patients the diagnosis was confirmed by histopathology after the surgery. Tumours were nodular, cystic or solid-cystic, often encapsulated (Fig. 1). Some of them were received as irregular fragmented pieces, as intact removal was not possible. Cut surfaces were partly greywhite and partly tan-brown with cystic degeneration. Areas of necrosis and hemorrhage were present in all the specimens.

\section{Preparation of the sample:}

The specimens were usually received in fixative (preservative) but sometimes arrived as fresh and were immediately fixed. Larger specimens required further dissection to produce representative pieces from appropriate areas. For example, multiple samples were taken from the excision margins of a tumour to ensure that the tumour has been completely removed. In the case of small specimens, the entire specimen was processed. The tissues selected for processing were placed in cassettes, and loaded onto a tissue processor for processing through to wax. After processing, the specimens were placed in an embedding centre where they are removed from their cassettes and placed in wax-filled molds. The specimen "block" was then allowed to solidify on a cold surface, and when set, the mold was removed. Paraffin sections are usually cut at a thickness of 3-5um with microtome. They were further processed and finally stained with hematoxylin and eosin (H\&E) stain.

\section{Microscopic features:}

Varying combinations of solid and pseudopapillary growth patterns with cystic areas. The pseudopapillary architectures were characterized by the arrangement of several layers of tumor cells around delicate fibrovascular cores. The cystic areas were filled with bland and loosely cohesive cells and fresh blood. The individual tumor cells were small to medium sized, round-ovoid shaped, with ovoid-elongated and eccentrically placed nuclei. Mitoses were rare (Fig. 2).

Data were collected, compiled and presented as tables as applicable. The study was approved by the Department of Pathology, Bangabandhu Sheikh Mujib Medical University (BSMMU), Dhaka, Bangladesh.

\section{Results}

The age range was of $14-45$ years (mean age 26.9 \pm 3.7 years) (Table-I). Among the tumours, 18 were found in female patients, while only 1 was from male patient. In all the cases, preoperative imaging contributed to diagnosis of an abdominal mass in the patients. 11 of these were reported as pancreatic mass, while 3 as pancreatic cystic mass, 2 as retroperitoneal mass, 2 as mesenteric mass and only 1 as adrenal 
mass (Table-II), (Table-III). Tumour-size ranged from 6 to $19 \mathrm{~cm}$ (mean size $9.3 \pm 1.5$ $\mathrm{cm}$ ) (Table-IV). 7 tumours were solid and cystic in nature, while 8 were solid and 4 were only cystic. Complete capsule was found in 17 specimens. Calcifications were found in only 5 specimens (Table-V).

Table-I: Age distribution of the patients.

\begin{tabular}{|l|c|c|}
\hline Age group & Number & Percentage \\
\hline$<20$ years & 7 & 36.85 \\
\hline $20-29$ years & 5 & 26.31 \\
\hline $30-39$ years & 5 & 26.31 \\
\hline 40 years and above & 2 & 10.53 \\
\hline
\end{tabular}

Table-II: Preoperative imaging results.

\begin{tabular}{|l|c|c|}
\hline Imaging results & Number & Percentage \\
\hline Pancreatic mass & 11 & 57.89 \\
\hline Pancreatic cystic mass & 3 & 15.79 \\
\hline Retroperitoneal mass & 2 & 10.53 \\
\hline Mesenteric mass & 2 & 10.53 \\
\hline Adrenal mass & 1 & 5.26 \\
\hline
\end{tabular}

Table-III: Associated tissue found with the tumour.

\begin{tabular}{|l|c|}
\hline Associated gross findings & Number \\
\hline Gall bladder removed & 3 \\
\hline Part of intestine removed & 3 \\
\hline Part of spleen removed & 3 \\
\hline Lymph node found & 2 \\
\hline
\end{tabular}

Table-IV: Tumour size.

\begin{tabular}{|l|c|c|}
\hline Tumour Size & Number & Percentage \\
\hline $1-5 \mathrm{~cm}$ & 4 & 21.05 \\
\hline $6-10 \mathrm{~cm}$ & 8 & 42.11 \\
\hline $11-15 \mathrm{~cm}$ & 5 & 26.31 \\
\hline $16-20 \mathrm{~cm}$ & 2 & 10.53 \\
\hline
\end{tabular}

Table-V: Histopathological pattern of the tumours.

\begin{tabular}{|l|c|c|}
\hline $\begin{array}{c}\text { Tumour } \\
\text { characteristics }\end{array}$ & Number & Percentage \\
\hline Component of tumor \\
\hline Solid and cystic & 7 & 36.84 \\
\hline Solid & 8 & 42.11 \\
\hline Cystic & 4 & 21.05 \\
\hline Pattern of capsule \\
\hline Complete & 17 & 89.47 \\
\hline Incomplete & 2 & 10.53 \\
\hline Calcification & 5 & 26.32 \\
\hline Present & 14 & 73.68 \\
\hline Absent
\end{tabular}

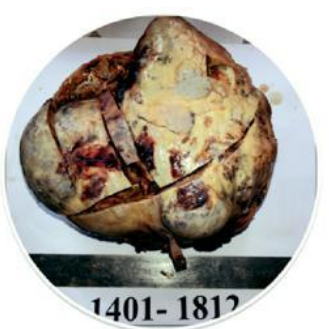

Fig.1. Gross appearance of the tumour, as collected from a 39 year-old female.

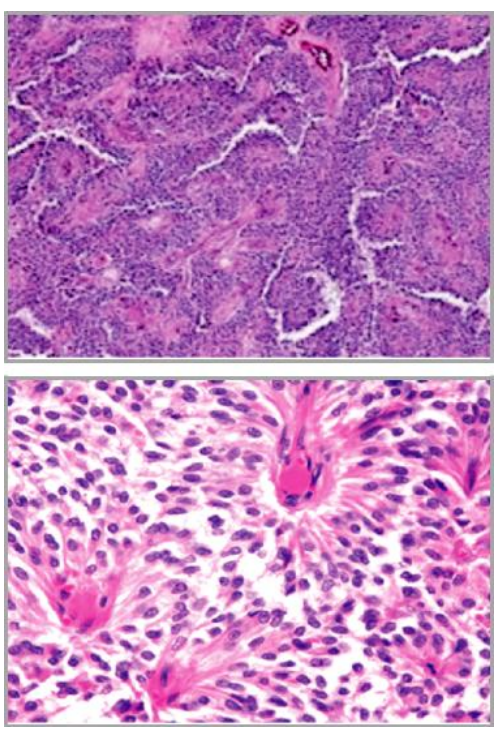

Fig. 2. Solid-pseudopapillary neoplasm (SPN) of the pancreas. 


\section{Discussion}

Solid-pseudopapillary neoplasm (SPN) of pancreas, a rare neoplasm, is characterized by a well-encapsulated mass with low malignant potential, common in young women within the second or third decade of life, and may occasionally diagnosed in children. ${ }^{1,2,5}$ In our study, majority of the patients were women who were below 20 years of age. Many literatures reported the highest incidence of SPN in the second decade of life..$^{3-7,9-10}$ Our study reported only one male patient diagnosed with SPN of pancreas at the age of 38 years. Tumors are frequently asymptomatic or minimally symptomatic, and also can reach a large size, with a mean of $10 \mathrm{~cm}$ at diagnosis. However, it may occur in every part of the pancreas, slightly more common in the head and sometimes in tail. Extrahepatic cases also been reported namely retroperitonium, mesentery and adrenal mass (usually left). ${ }^{5,11-14}$

Evidence suggested that this tumour is mostly encapsulated, complex mass with both solid and cystic components, often with displacement of nearby structures ${ }^{2-4,12-14}$, as similar to our study reports. Histopathology is essential for final diagnosis of SPN. ${ }^{10}$ Characteristic light microscopic features are: solid areas alternating with pseudopapillary formations and cystic changes; evidence of cellular degeneration, including cholesterol clefts and aggregates of foamy histiocytes; nuclear grooves; and aggregates of hyaline cytoplasmic globules, at least focally, in every case. ${ }^{8,10}$ There is no relation between biological behaviour and malignant potential of SPN in relation to known clinical criteria and histologic features. ${ }^{1,10}$ The line of cellular differentiation reflected in SPNs remains unclear; therefore, immunehistochemical staining for specific cell lineage markers is of marginal utility in proving the diagnosis of SPN. ${ }^{10}$ Complete resection is curative in most cases.

Conservative resection with preservation of as much pancreatic tissue as possible is the treatment of choice. ${ }^{2,10}$ There is no clear role for systemic therapy, radiotherapy in case of malignancy, inoperable tumor or relapse. ${ }^{10,15}$ Prognostic factors are not wellestablished and clinical evolution cannot be predicted in most cases. In approximately $85 \%$ of the patients, SPN is limited to the pancreas at the time of presentation, while about $10 \%$ to $15 \%$ of tumors present with metastasis. ${ }^{5,12,16}$ Nonetheless, in our study, absence of metastasis suggests that these tumours hardly show aggressive clinical behaviour. However, follow-up is important for potential of local recurrence and appearance of metastasis, which may affect most commonly liver, regional lymph node, mesentery, omentum and peritoneum. ${ }^{2,10}$ Surgical resection of the primary tumor and metastases is the treatment of choice. ${ }^{1}$

\section{Conclusion:}

To summarize, SPN of pancreas is a rare neoplasm that primarily affects young women. These are detected by imaging and final diagnosis is done by histopathology. Surgical resection is generally curative.

\section{References:}

1. Zhang $H$, Liang TB, Wang $W L$, Shen $Y$, Ren GP, Zheng SS. Diagnosis and treatment of solid-pseudopapillary tumor of the pancreas. Hepatobiliary Pancreat Dis Int. 2006;5(3):454-8.

2. Papavramidis $T$, Papavramidis S. Solid pseudopapillary tumors of the pancreas: review of 718 patients reported in English literature. J Am Coll Surg. 2005;200(6):96572.

3. Estrella JS, Li L, Rashid A, Wang H, Katz $M H$, Fleming JB, et al. Solid pseudopapillary neoplasm of the pancreas: clinicopathologic and survival analyses of 64 cases from a single institution. Am J Surg Pathol. 2014;38(2):147-57.

4. Yang $F$, Jin C, Long J, Yu XJ, Xu J, Di Y, et al. Solid pseudopapillary tumor of the pancreas: a case series of 26 consecutive patients. Am J Surg. 2009;198(2):210-5. 
5. Pettinato G, Di Vizio D, Manivel JC, Pambuccian SE, Somma $P$, Insabato $L$. Solid-pseudopapillary tumor of the pancreas: a neoplasm with distinct and highly characteristic cytological features. Diagn Cytopathol. 2002;27(6):325-34.

6. Patil TB, Shrikhande SV, Kanhere HA, Saoji RR, Ramadwar MR, Shukla PJ. Solid pseudopapillary neoplasm of the pancreas: a single institution experience of 14 cases. HPB (Oxford). 2006;8(2):148-50.

7. Tipton SG, Smyrk TC, Sarr MG, Thompson GB. Malignant potential of solid pseudopapillary neoplasm of the pancreas. Br J Surg. 2006;93(6):733-7.

8. Klöppel G, Hruban RH, Klimstra DS, Maitra $A$, Morohoshi $T$, Notohara $K$, et al. Solidpseudopapillary tumor of pancreas. In: Bosman FT, Carneiro F, Hruban RH, Theise $N D$, editors. World Health Organization Classification of Tumours of the Digestive System. Lyon: IARC; 2010. p.327-30.

9. Song H, Dong M, Zhou J, Sheng W, Zhong B, Gao W. Solid Pseudopapillary Neoplasm of the Pancreas: Clinicopathologic Feature, Risk Factors of Malignancy, and Survival Analysis of 53 Cases from a Single Center. Biomed Res Int. 2017;2017:5465261.

10. Hosokawa I, Shimizu H, Ohtsuka M, Kato A, Yoshitomi H, Furukawa $K$, et al. Preoperative diagnosis and surgical management for solid pseudopapillary neoplasm of the pancreas. J Hepatobiliary Pancreat Sci. 2014;21(8):573-8.

11. Geers C, Moulin P, Gigot JF, Weynand B, Deprez P, Rahier J, Sempoux C. Solid and pseudopapillary tumor of the pancreas-review and new insights into pathogenesis. Am J Surg Pathol. 2006;30(10):1243-9.

12. Uppin SG, Hui M, Thumma V, Challa $S$, Uppin MS, Bheerappa $N$, et al. Solidpseudopapillary neoplasm of the pancreas: a clinicopathological and immunohistochemical study of 33 cases from a single institution in Southern India. Indian J Pathol Microbiol. 2015;58(2):163-9.

13. Yu PF, Hu ZH, Wang XB, Guo JM, Cheng $X D$, Zhang $Y L$, et al. Solid pseudopapillary tumor of the pancreas: A review of 553 cases in Chinese literature. World $J$ Gastroenterol. 2010;16(10):1209-14.
14. Yagcı A, Yakan S, Coskun A, Erkan N, Yıldırım M, Yalcın E, Postacı H. Diagnosis and treatment of solid pseudopapillary tumor of the pancreas: experience of one single institution from Turkey. World J Surg Oncol. 2013;11:308.

15. Fried P, Cooper J, Balthazar E, Fazzini E, Newall J. A role for radiotherapy in the treatment of solid and papillary neoplasms of the pancreas. Cancer. 1985;56(12):2783-5.

16. Sperti $C$, Berselli $M$, Pasquali $C$, Pastorelli $D$, Pedrazzoli S. Aggressive behaviour of solidpseudopapillary tumor of the pancreas in adults: a case report and review of the literature. World J Gastroenterol. 2008;14(6):960-5. 